Article

\title{
Biomechanical Design Application on the Effect of Different Occlusion Conditions on Dental Implants with Different Positions-A Finite Element Analysis
}

\author{
Pei-Ju Lin ${ }^{1}$ and Kuo-Chih Su ${ }^{2,3, *(1)}$ \\ 1 Department of Commercial Design, National Taichung University of Science and Technology, \\ Taichung 404, Taiwan; adobe33@nutc.edu.tw \\ 2 Department of Medical Research, Taichung Veterans General Hospital, Taichung 407, Taiwan \\ 3 Department of Biomedical Engineering, Hungkuang University, Taichung 433, Taiwan \\ * Correspondence: kcsu@vghtc.gov.tw; Tel.: +886-4-23592525 (ext. 5153)
}

Received: 23 July 2020; Accepted: 21 August 2020; Published: 23 August 2020

\begin{abstract}
A dental implant is currently the most commonly used treatment for patients with lost teeth. There is no biomechanical reference available to study the effect of different occlusion conditions on dental implants with different positions. Therefore, the aim of this study was to conduct a biomechanical analysis of the impact of four common occlusion conditions on the different positions of dental implants using the finite element method. We built a finite element model that included the entire mandible and implanted seven dental implant fixtures. We also applied external force to the position of muscles on the mandible of the superficial masseter, deep masseter, medial pterygoid, anterior temporalis, middle temporalis, and posterior temporalis to simulate the four clenching tasks, namely the incisal clench (INC), intercuspal position (ICP), right unilateral molar clench (RMOL), and right group function (RGF). The main indicators measured in this study were the reaction force on the temporomandibular joint (TMJ) and the fixed top end of the abutment in the dental implant system, and the stress on the mandible and dental implant systems. The results of the study showed that under the occlusion conditions of RMOL, the dental implant system (113.99 MPa) and the entire mandible (46.036 MPa) experienced significantly higher stress, and the reaction force on the fixed-top end of the abutment in the dental implant system $(261.09 \mathrm{~N})$ were also stronger. Under the occlusion of ICP, there was a greater reaction force $(365.8 \mathrm{~N})$ on the temporomandibular joint. In addition, it was found that the reaction force on the posterior region $(26.968 \mathrm{~N}$ to $261.09 \mathrm{~N})$ was not necessarily greater than that on the anterior region $(28.819 \mathrm{~N}$ to $70.431 \mathrm{~N})$. This information can help clinicians and dental implant researchers understand the impact of different chewing forces on the dental implant system at different positions after the implantation.
\end{abstract}

Keywords: biomechanics; dental implant; finite element analysis; occlusion conditions

\section{Introduction}

The dental implant treatment is currently one of the major treatment methods for patients with lost teeth. Although the success rate of dental implants is very high [1], the most common factors of implant failure for late losses after implant placement are bacterial-induced marginal bone loss (peri-implantitis) and excessive occlusal stress [2]. The overloading on dental implants has always been one of the main causes of implant failure [3]. Therefore, the biomechanics of dental implants is a topic that has received great attention from many researchers.

Most dental implant systems mainly consist of the dental implant, abutment, screw, crown, and other structures. Therefore, many studies have conducted research on the different designs of the 
different structures. The most common topic of study is the biomechanical analysis of the length and diameter of the dental implant [4-6]. From a mechanical point of view, the longer the implant and the larger the diameter, the greater the contact area between the dental implant and the mandible will be, making the implant more resistant to mechanical load. However, sometimes due to the structural limitations of the patient's mandible, it is not possible to use long, thick dental implants. Moreover, some researches have also conducted a biomechanical analysis with regard to the geometric design of the flute shape, thread shape, abutment, screw, and crown of the dental implant [7-12]. In addition, the material of the implant is also a popular research topic $[13,14]$. Regarding the bone structure, there are also biomechanical studies on the bone-implant contact interface [15]. Although there are a number of studies on the design of the dental implant systems, due to the complex structure of the mandible, most studies only evaluated a single tooth and did not analyze in detail the influence of the different positions of the implant. Previous literature has pointed out that the posterior teeth bear greater occlusal forces than the anterior teeth [16], and thus the dental implant system in the posterior teeth region is more likely to be damaged [17]. Therefore, when evaluating the biomechanics of the dental implants, the impact of the different implantation positions should also be taken into account.

The most common external force received by the dental implant system is the occlusal force generated by chewing. The magnitude of the bite force may be dissimilar due to the different areas of bite [18]. Most biomechanical studies of dental implant systems usually apply only a single vertical, horizontal, or oblique loading to evaluate the effect of the load after the implantation. They also fail to take into account the impact of muscles during the chewing movements, and thus, the actual conditions of the dental implants are usually different from the experimental results. Therefore, if the mechanical effects of the different occlusion conditions on the dental implants are also considered during the experiment, we will be able to simulate the actual conditions of the dental implants more closely. At present, finite element analysis (FEA) is a commonly used analysis method in the field of dental biomechanics [19]. The FEA is a numerical method of analysis for deformations and stresses in any given structure [20]. Many studies have used FEA before. Based on previous literature, they explored how the mandible was affected under different occlusion conditions (simulations of incisal clench (INC), intercuspal position (ICP), right unilateral molar clench (RMOL), right group function (RGF), etc., the data for the loading and boundary conditions were obtained from a previous study by Korioth and Hannam [21]). They used the finite element analysis to conduct the biomechanical analysis of the impact of different occlusion conditions on the implantation of the total temporomandibular joint, the scaffold for the reconstruction of the mandibular defects, for bilateral sagittal split osteotomy, and the mandible and condylar fracture osteosynthesis [22-25]. Therefore, the loading conditions and boundary conditions set in the FEA are also suitable for simulating and evaluating the forces exerted to the dental implant system under different occlusion conditions.

As shown in the aforementioned studies, the dental implant treatment is currently the most commonly used treatment method for patients with lost teeth. However, due to the complex structure of the oral cavity, most of the previous biomechanics studies only focused on a single tooth and used a simple external force (vertical, horizontal, or oblique loading) in the biomechanical evaluation of the dental implant system [26]. Although the results of the previous studies greatly facilitate the design and improvement of dental implants, they are still different from the actual occlusions. The external force on dental implants should be closer to the actual loading conditions when performing biomechanics experiments. The dental implants in different positions should be subjected to different external forces under different occlusion situations. Therefore, the main objective of this study is to conduct a biomechanical analysis of the impact of four common occlusion conditions on dental implants with different positions using the finite element method. Furthermore, the investigation of the posterior region is subject to a larger external force when biting. The results of this study provide a biomechanical reference and can help clinicians, and dental implant researchers understand the impact of different chewing forces on the dental implant system at different positions after the implantation. 


\section{Materials and Methods}

\subsection{Building a Simulation Geometry Model}

To explore the mechanical impact on dental implants at different positions in 4 different clenching tasks after implantation, this study digitally built a finite element model of the mandible with dental implants at different positions. The 5 main structures included in our computer model were the mandibular cortical bone, mandibular trabecular bone, dental implant, abutment, and abutment screw (Figure 1). The construction of the model of the mandible was mainly based on the computed tomography (CT) images provided by the Visible Human Project from the US National Institutes of Health. Using the medical image reconstruction software Mimics (Mimics Medical 20.0, Materialise, Leuven, Belgium), we performed segmentation on the CT images and reconstructed the human mandible. In addition, using the grayscale value of the CT image, we differentiated the cortical bone from the trabecular bone of the mandible, and thus the mandible model constructed in our study can be divided into 2 parts, cortical bone and trabecular bone. For the construction of the model of the dental implant system, we mainly used the 3D computer-aided design (CAD) software (Solidworks 2016, Dassault Systems SolidWorks Corp, Waltham, MA, USA).

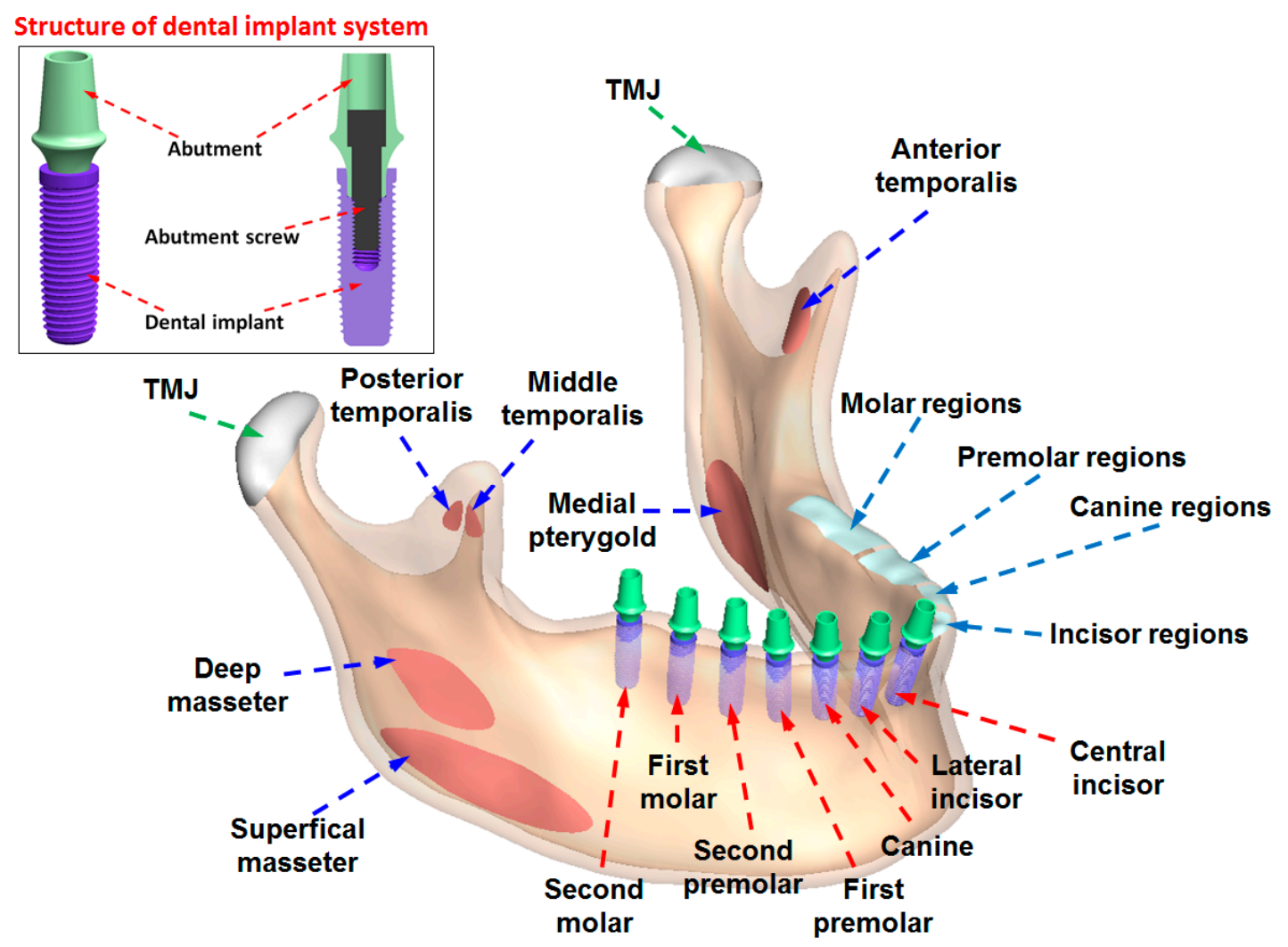

Figure 1. The computer model for FEA used in this study (including the structure of the dental implant system, the positions of the muscles related to the occlusion of the mandible, the positions of different occlusion regions, and the positions of the implants on the mandible).

The model of the dental implant system was built mainly according to the recommendations of previous studies [27], and the final product was $12 \mathrm{~mm}$ in length and $4 \mathrm{~mm}$ in diameter. In addition, the structures of the abutment and the abutment screw were also constructed [28]. To examine the biomechanical impact of different occlusions on dental implants at different positions, this study constructed 7 dental implant fixtures on the computer model of the mandible according to the positioning of the teeth, and the implants were placed at the central incisor, lateral incisor, canine, first premolar, second premolar, first molar, and second molar. (The third molar was a wisdom tooth; 
therefore, this study did not consider establishing an implant model at the location.) After 3D computer modeling of the mandible with the dental implant systems, the model was imported into the FEA software ANSYS Workbench (ANSYS Workbench 18.0, ANSYS, Inc., Canonsburg, PA, USA).

\subsection{Loading and Boundary Conditions}

This study examined the effect of 4 different occlusion conditions commonly seen in clinical practice on the dental implant system. The 4 clenching tasks were incisal clench (INC), intercuspal position (ICP), right unilateral molar clench (RMOL), and right group function (RGF). In the FEA, different loading conditions and boundary conditions were given according to these 4 occlusion conditions. The values of the loading and boundary conditions were set with reference to previous literature [21-25]. For the loading conditions, external forces were applied on the position of muscles on the mandible of the superficial masseter (SM), deep masseter (DM), medial pterygoid (MP), anterior temporalis (AT), middle temporalis (MT), and posterior temporalis (PT) (Figure 2a-d). The values and directions of the external forces are shown in Table 1.

Table 1. The loading conditions in this study, values, and directions of the external forces applied in different occlusion conditions, and fixed-top end of the abutment in the dental implant system [21-25].

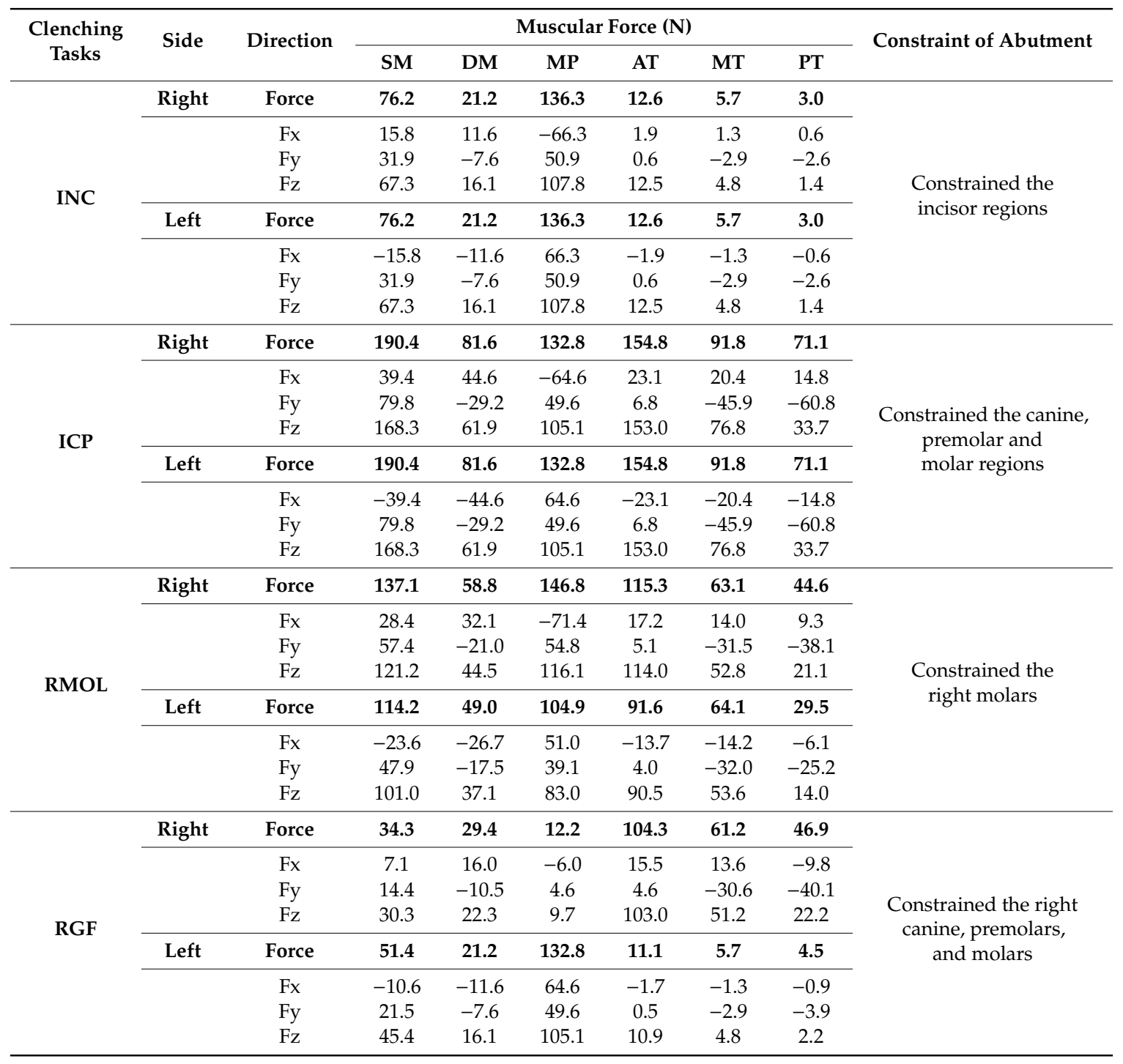


(a)

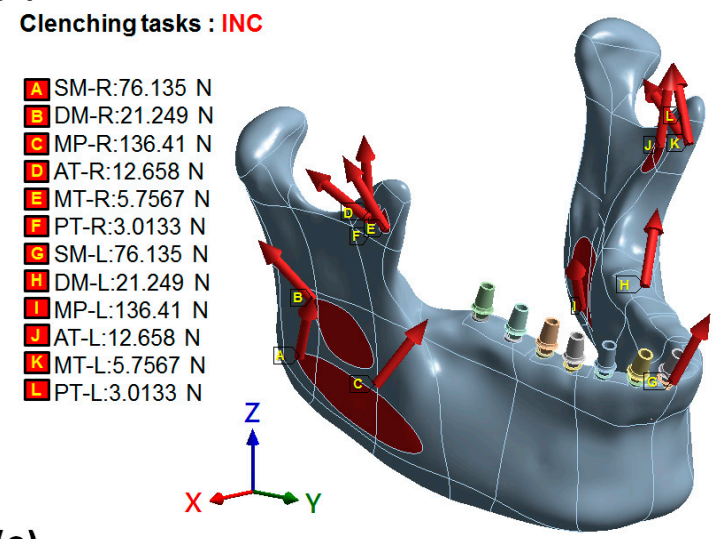

(c)

Clenching tasks : RMOL

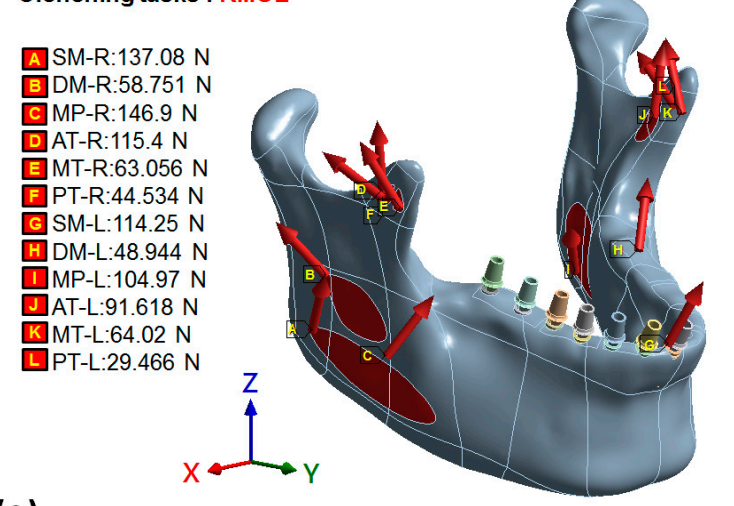

(e)

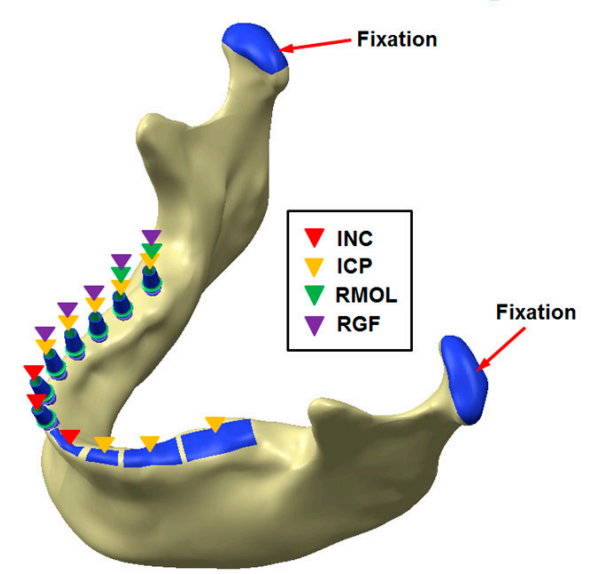

(b)
Clenching tasks : ICP

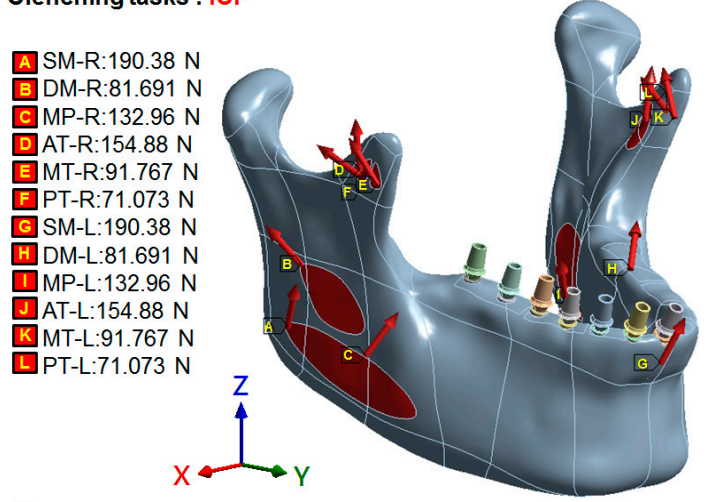

(d)

$$
\text { Clenching tasks : RGF }
$$

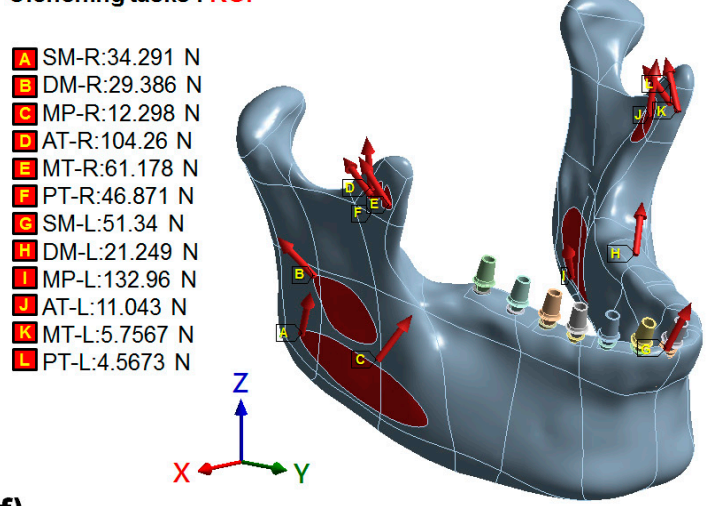

(f)

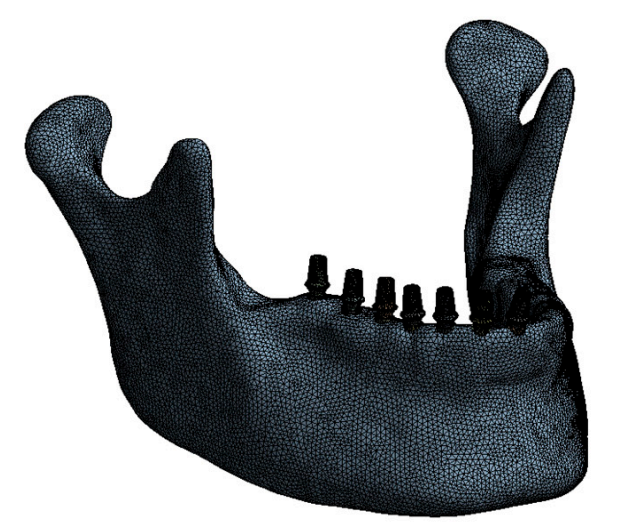

Figure 2. (a) The forces exerted by the muscles in the incisal clench (INC), (b) the forces exerted by the muscles in the intercuspal position (ICP) (c) the forces exerted by the muscles in the right unilateral molar clench (RMOL), (d) the forces exerted by the muscles in the right group function (RGF). (e) The boundary conditions of this study (Blue area): According to the different occlusion conditions, the top end of the abutment in the dental implant system, the occlusion regions, and the temporomandibular joint (TMJ) were fixed. (f) The mesh of the computer model in this study.

For the boundary conditions (Figure 2e), the temporomandibular joint (TMJ) was set as the fixed end and the displacements on the $\mathrm{X}$-axis, $\mathrm{Y}$-axis, and $\mathrm{Z}$-axis in this region were set to 0 . In addition, according to each clenching task, the top end of the abutment in the dental implant system was fixed at the incisor, canine, premolar, and molar to simulate the actual conditions of teeth occlusions. INC mainly simulates the contact between incisal edges (therefore, the tops of the abutments of the implants at the central incisor, lateral incisor and the regions of incisors were fixed). ICP simulates the maximum intercuspation of the posterior teeth (the tops of the abutments of the implants at the 
canine, first premolar, second premolar, first molar, second molar, and the regions of canines, premolars, molars were fixed). RMOL simulates the contact of the posterior teeth on the right side (unilateral) (the tops of the abutments of the implants at the first molar and second molar were fixed). RGF simulates the lateral movement of the right posterior teeth (the tops of the abutments of the implants at the canine, first premolar, second premolar, first molar, and second molar were fixed).

\subsection{Material Properties of the Model}

The finite element model of this study consisted of 5 parts, including the mandibular cortical bone, mandibular trabecular bone, dental implant, abutment, and abutment screw. The properties of the materials used in this study were obtained from previous literature [26,29]. The materials of the dental implant, abutment, and abutment screw were set to Titanium. Table 2 shows the material properties used in the simulation of this study. All materials were assumed to be homogeneous, isotropic, and linear elastic. Therefore, 2 independent parameters (Young's modulus (E) and Poisson's ratio $(v))$ were used to represent the properties of the materials. In addition, the mesh element used in the finite element computer model was a tetrahedral mesh (Figure 2f). The meshes were subject to the convergence test and 5\% was the stop criteria of the convergence test [30]. Thus, it was suitable to use the finite element mesh model in this study to explore the effect of different occlusion conditions on the dental implant system. The number of nodes and elements of our computer finite element model was $1,407,947$ and 893,965 , respectively.

Table 2. Settings of the Material properties in this study $[27,30]$.

\begin{tabular}{cccc}
\hline & Material & Young's Modulus (MPa) & Poisson's Ratio \\
\hline Cortical bone & - & 13,800 & 0.26 \\
Trabecular bone & - & 345 & 0.31 \\
Dental implant & Titanium & 110,000 & 0.35 \\
Abutment & Titanium & 110,000 & 0.35 \\
Abutment screw & Titanium & 110,000 & 0.35 \\
\hline
\end{tabular}

After the FEA was performed, the main observation indicators of this study were the reaction force at the TMJ and the fixed top end of the abutment in the dental implant system, the von Mises stress on the mandibular bone, the von Mises stress on the dental implant, the Von Mises stress on the abutment, and the von Mises stress on the abutment screw (von Mises stress is defined as $\sigma_{\text {von }}=\sqrt{\frac{1}{2}\left[\left(\sigma_{1}-\sigma_{2}\right)^{2}+\left(\sigma_{1}-\sigma_{3}\right)^{2}+\left(\sigma_{2}-\sigma_{3}\right)^{2}\right]}$, where $\sigma 1, \sigma 2$, and $\sigma 3$ represent the principal stress along the three axes.) Based on these observation indicators, we conducted biomechanical analysis of the effect of the four different clenching tasks on dental implants at different positions.

\section{Results}

The FEA showed the distribution of the reaction forces and structural stress at the fixed top end of the abutment in the dental implant system. Figure 3 shows the value and direction of the reaction force at the TMJ and the fixed end of the abutment under the four occlusion conditions in this study. As shown in the figure, under the RMOL conditions, the reaction force at the top of the abutment of the dental implant system was larger. Furthermore, in the case of ICP conditions, the TMJ has a larger reaction force. Table 3 shows the magnitude of the reaction force at the TMJ and the top of the abutment and the magnitudes of the composing forces along each axis under the four occlusion conditions. 
Table 3. The magnitude of the reaction force at the top of the abutment and TMJ. The magnitudes of the composing forces along each axis under the four occlusion conditions.

\begin{tabular}{|c|c|c|c|c|c|c|c|c|c|c|}
\hline $\begin{array}{c}\text { Clenching } \\
\text { Tasks }\end{array}$ & Force & $\begin{array}{l}\text { Central } \\
\text { Incisor }\end{array}$ & $\begin{array}{l}\text { Lateral } \\
\text { Incisor }\end{array}$ & Canine & $\begin{array}{c}\text { First } \\
\text { Premolar }\end{array}$ & $\begin{array}{c}\text { Second } \\
\text { Premolar }\end{array}$ & First Molar & $\begin{array}{c}\text { Second } \\
\text { Molar }\end{array}$ & Right TMJ & Left TMJ \\
\hline \multirow{4}{*}{ INC } & Total & $38.340 \mathrm{~N}$ & $70.431 \mathrm{~N}$ & \multirow{4}{*}{ - } & \multirow{4}{*}{ - } & \multirow{4}{*}{-} & \multirow{4}{*}{-} & \multirow{4}{*}{ - } & $182.31 \mathrm{~N}$ & $184.72 \mathrm{~N}$ \\
\hline & Fx & $5.1629 \mathrm{~N}$ & $14.662 \mathrm{~N}$ & & & & & & $-17.976 \mathrm{~N}$ & $20.411 \mathrm{~N}$ \\
\hline & Fy & $-31.503 \mathrm{~N}$ & $-67.652 \mathrm{~N}$ & & & & & & $31.692 \mathrm{~N}$ & $30.499 \mathrm{~N}$ \\
\hline & $\mathrm{Fz}$ & $-21.235 \mathrm{~N}$ & $-12.992 \mathrm{~N}$ & & & & & & $-178.63 \mathrm{~N}$ & $-181.04 \mathrm{~N}$ \\
\hline \multirow{4}{*}{ ICP } & Total & \multirow{4}{*}{ - } & \multirow{4}{*}{ - } & $28.819 \mathrm{~N}$ & $40.884 \mathrm{~N}$ & $61.691 \mathrm{~N}$ & $80.588 \mathrm{~N}$ & $161.13 \mathrm{~N}$ & $365.80 \mathrm{~N}$ & $357.11 \mathrm{~N}$ \\
\hline & Fx & & & $25.614 \mathrm{~N}$ & $16.475 \mathrm{~N}$ & $21.270 \mathrm{~N}$ & $17.391 \mathrm{~N}$ & $15.037 \mathrm{~N}$ & $-75.501 \mathrm{~N}$ & $73.586 \mathrm{~N}$ \\
\hline & Fy & & & $7.8226 \mathrm{~N}$ & $-13.908 \mathrm{~N}$ & $-21.296 \mathrm{~N}$ & $-35.744 \mathrm{~N}$ & $-90.697 \mathrm{~N}$ & $147.24 \mathrm{~N}$ & $144.29 \mathrm{~N}$ \\
\hline & $\mathrm{Fz}$ & & & $10.643 \mathrm{~N}$ & $-34.737 \mathrm{~N}$ & $-53.850 \mathrm{~N}$ & $-70.103 \mathrm{~N}$ & $-132.33 \mathrm{~N}$ & $-326.24 \mathrm{~N}$ & $-318.27 \mathrm{~N}$ \\
\hline \multirow{4}{*}{ RMOL } & Total & \multirow{4}{*}{ - } & \multirow{4}{*}{ - } & \multirow{4}{*}{-} & \multirow{4}{*}{ - } & \multirow{4}{*}{ - } & $261.09 \mathrm{~N}$ & $214.91 \mathrm{~N}$ & $176.2 \mathrm{~N}$ & $283.92 \mathrm{~N}$ \\
\hline & Fx & & & & & & $-78.035 \mathrm{~N}$ & $66.338 \mathrm{~N}$ & $-14.664 \mathrm{~N}$ & $30.062 \mathrm{~N}$ \\
\hline & Fy & & & & & & $-58.352 \mathrm{~N}$ & $-107.97 \mathrm{~N}$ & $85.602 \mathrm{~N}$ & $37.721 \mathrm{~N}$ \\
\hline & $\mathrm{Fz}$ & & & & & & $-242.22 \mathrm{~N}$ & $-173.58 \mathrm{~N}$ & $153.31 \mathrm{~N}$ & $-279.79 \mathrm{~N}$ \\
\hline \multirow{4}{*}{ RGF } & Total & \multirow{4}{*}{-} & \multirow{4}{*}{ - } & $60.942 \mathrm{~N}$ & $40.142 \mathrm{~N}$ & $26.968 \mathrm{~N}$ & $29.38 \mathrm{~N}$ & $42.832 \mathrm{~N}$ & $168.63 \mathrm{~N}$ & $134.06 \mathrm{~N}$ \\
\hline & Fx & & & $-45.555 \mathrm{~N}$ & $-8.0485 \mathrm{~N}$ & $4.8838 \mathrm{~N}$ & $4.8260 \mathrm{~N}$ & $5.3588 \mathrm{~N}$ & $-26.398 \mathrm{~N}$ & $-9.2242 \mathrm{~N}$ \\
\hline & Fy & & & $-28.842 \mathrm{~N}$ & $-17.589 \mathrm{~N}$ & $-11.427 \mathrm{~N}$ & $-12.513 \mathrm{~N}$ & $-19.927 \mathrm{~N}$ & $92.999 \mathrm{~N}$ & $-2.301 \mathrm{~N}$ \\
\hline & $\mathrm{Fz}$ & & & $-28.405 \mathrm{~N}$ & $-35.174 \mathrm{~N}$ & $-23.934 \mathrm{~N}$ & $-26.267 \mathrm{~N}$ & $-37.534 \mathrm{~N}$ & $-138.16 \mathrm{~N}$ & $-133.72 \mathrm{~N}$ \\
\hline
\end{tabular}


(a)

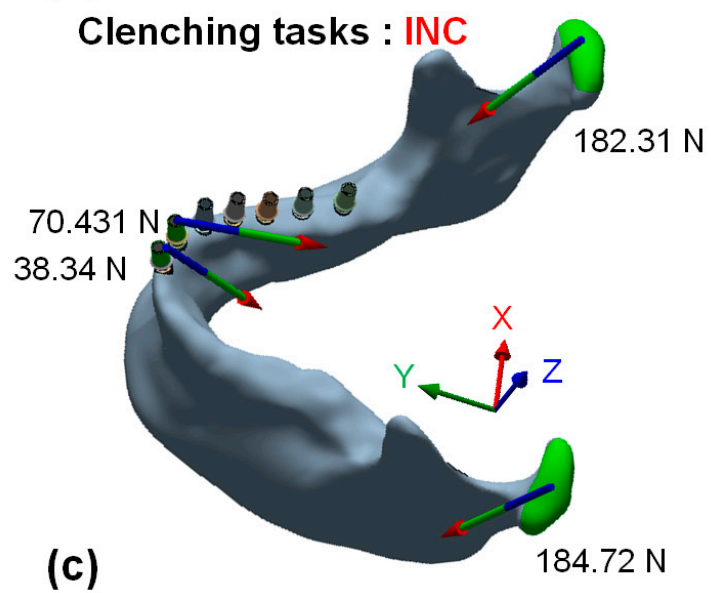

Clenching tasks : RMOL

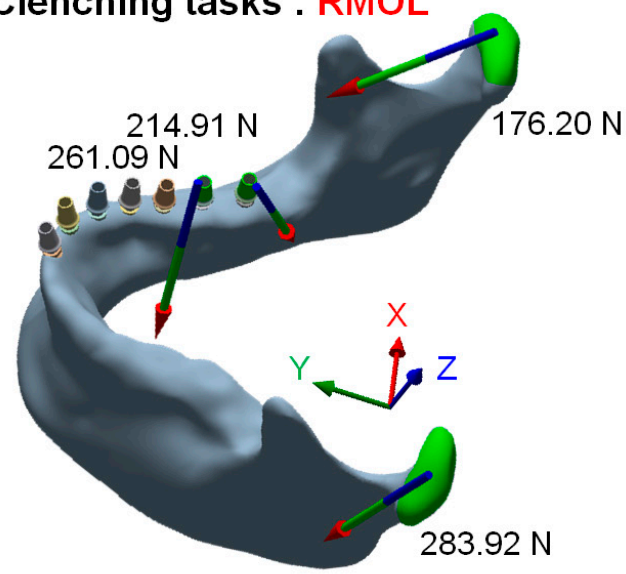

(b)
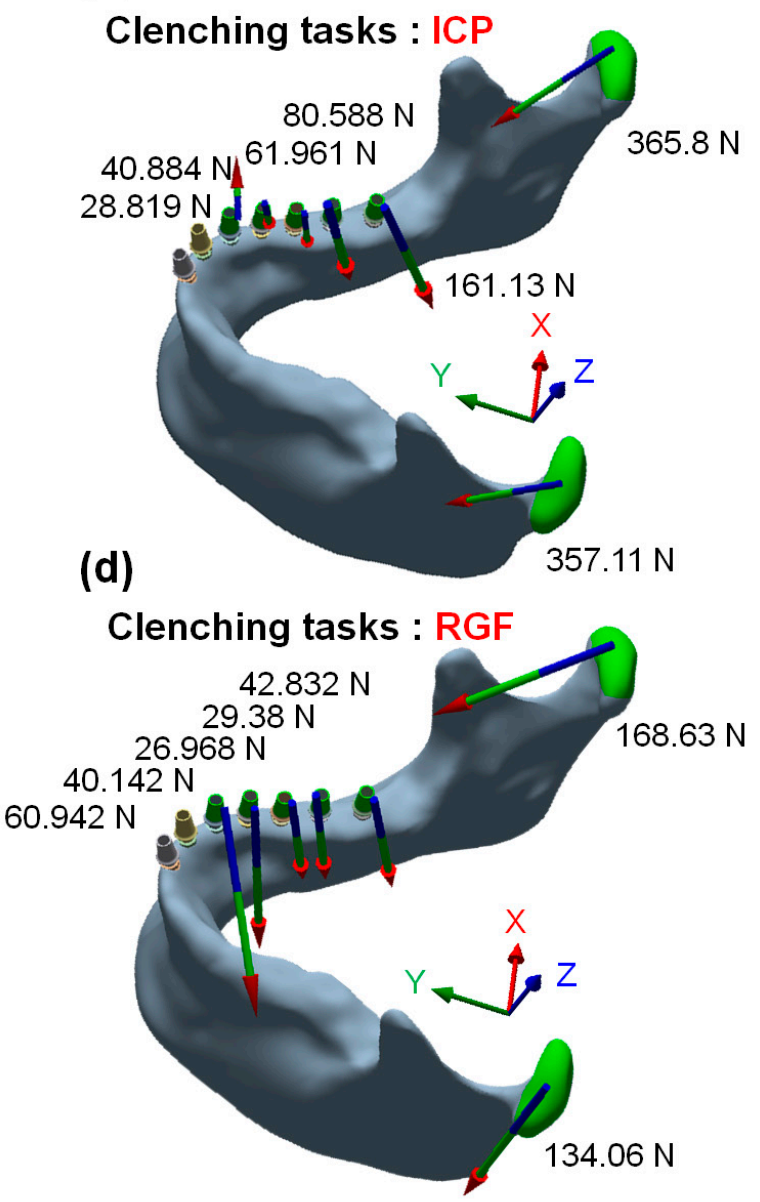

Figure 3. The magnitude and direction of the reaction forces at the TMJ and the top fixed end of the abutment under the four occlusion conditions. (a) Incisal clench (INC); (b) Intercuspal position (ICP); (c) Right unilateral molar clench (RMOL); (d) Right group function (RGF).

Figure 4a shows the distribution of von Mises stress in the mandibular bone under the four occlusion conditions. The figure shows that under all the four occlusion conditions, high stress arises at the neck near the TMJ. Under RMOL especially, the mandible is under significantly higher stress. In addition, depending on the boundary conditions, the tops of the abutments were fixed for the different occlusion conditions. The alveolar bones surrounding the fixed top ends of the abutments received higher stress. Figure $4 \mathrm{~b}$ shows the distribution of von Mises stress in the alveolar bone surrounding the implants at different positions under the 4 occlusion conditions. In addition to the high stress on the alveolar bones near the implants affected by the boundary conditions, the stress was also high on the cortical bone above the alveolar bone. Table 4 shows the peak value of von Mises stress in the alveolar bone at each implant position. The alveolar bones surrounding the implants affected by the fixed abutments under the boundary conditions have higher stress values.

Figure 5a shows the distribution of von Mises stress on the dental implants at different positions under the 4 occlusion conditions; Figure $5 \mathrm{~b}$ shows the distribution of von Mises stress on the abutments of each dental implant system; and Figure $5 \mathrm{c}$ shows the distribution of von Mises stress on the abutment screws of each dental implant system. The figure shows that high stresses mainly occur on implants affected by the boundary conditions. The high stresses on the dental implant arised at the junctions with the cortical bone. The high stresses on the abutments arised at the junctions with the dental implants. The high stress on the abutment screws arised in areas where the screw heads are connected to the abutments. Table 5 shows the maximum von Mises stress values on the dental 
implant, abutment, and abutment screw of the implants affected by the boundary conditions under the 4 occlusion conditions.

(a)

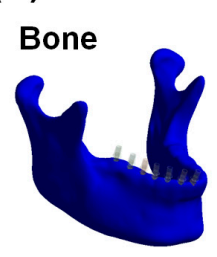

(b)
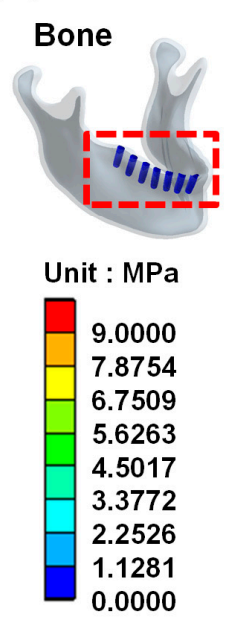

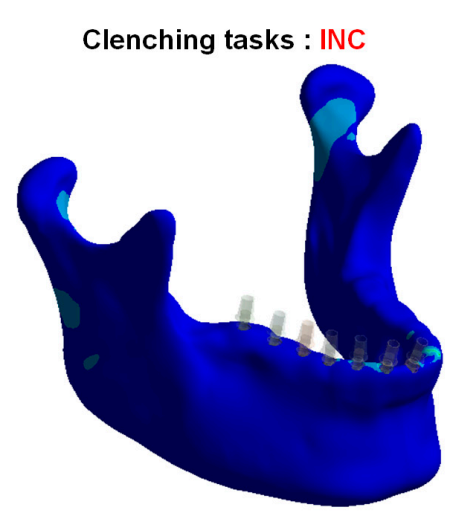

Clenching tasks : RMOL
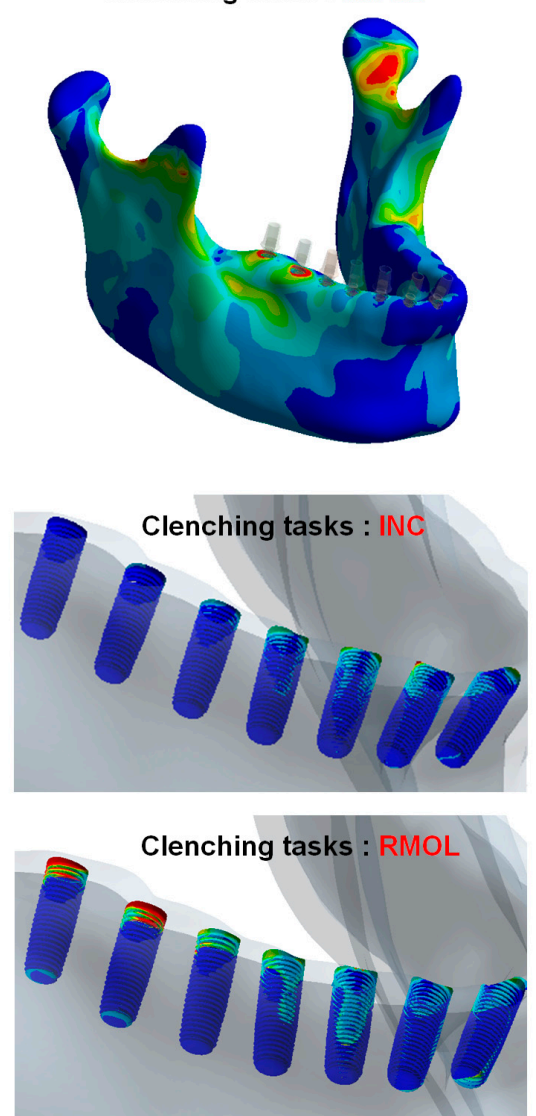

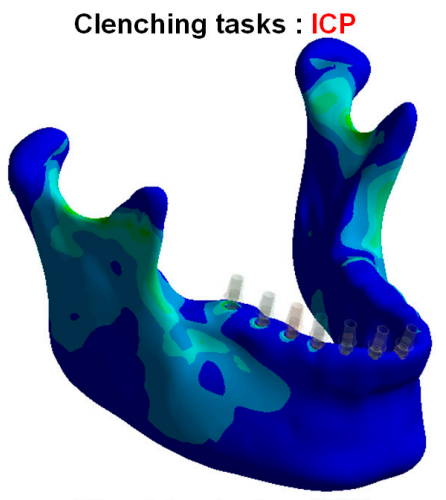

Clenching tasks : RGF
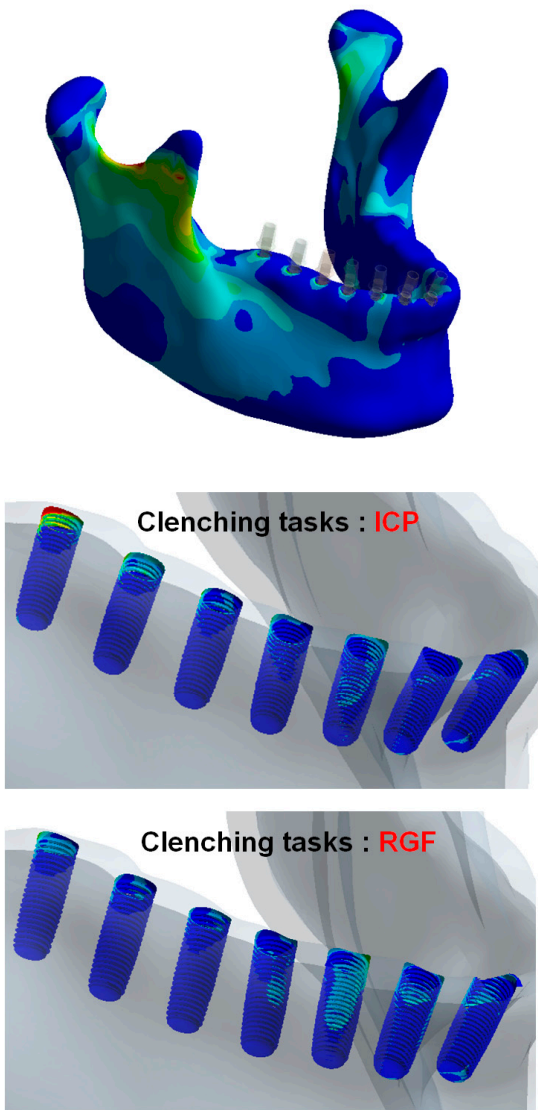

Figure 4. (a) Distribution of von Mises stress in the mandibular bone; (b) distribution of von Mises stress in the alveolar bone surrounding the implants. 
(a)
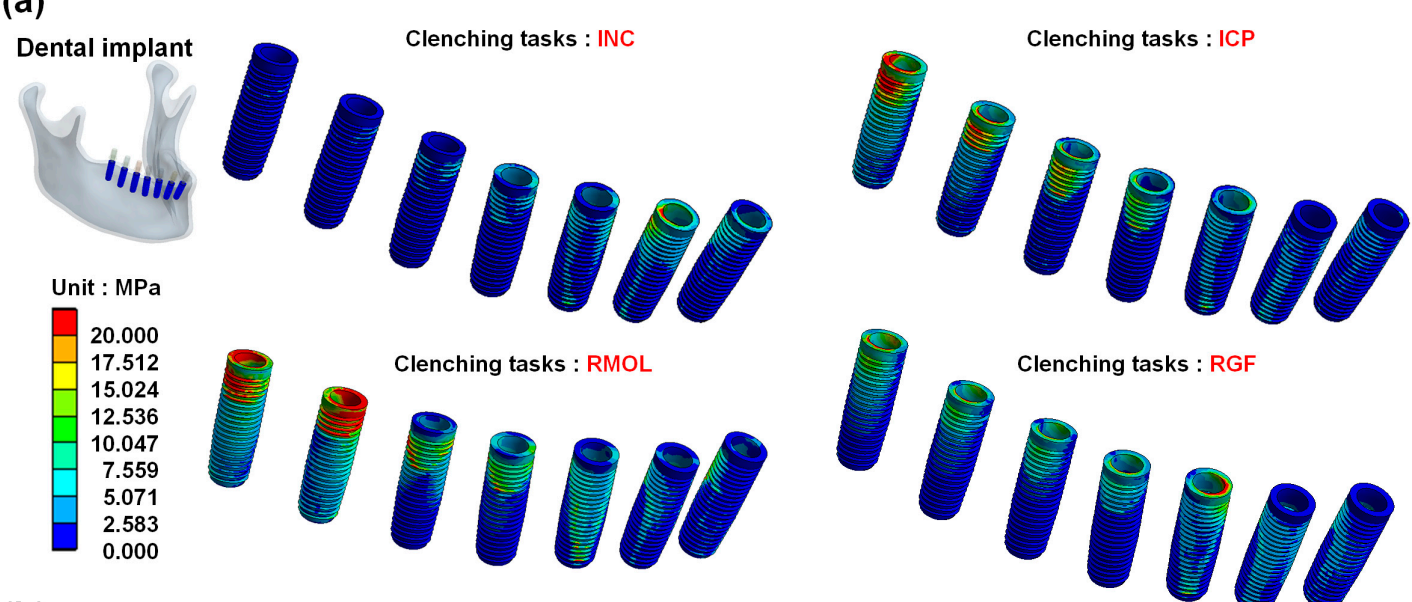

(b)
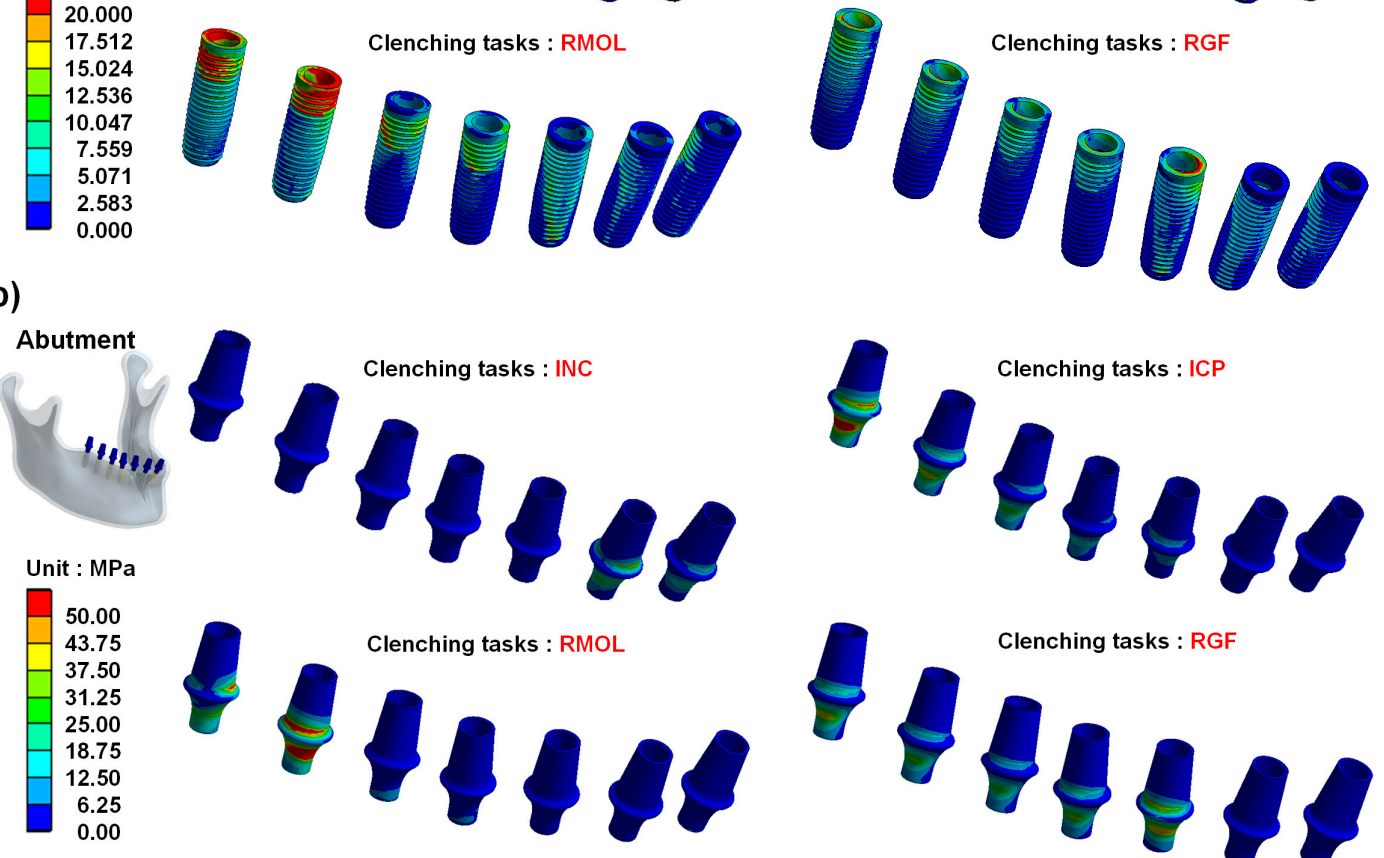

Clenching tasks : RGF

(c)

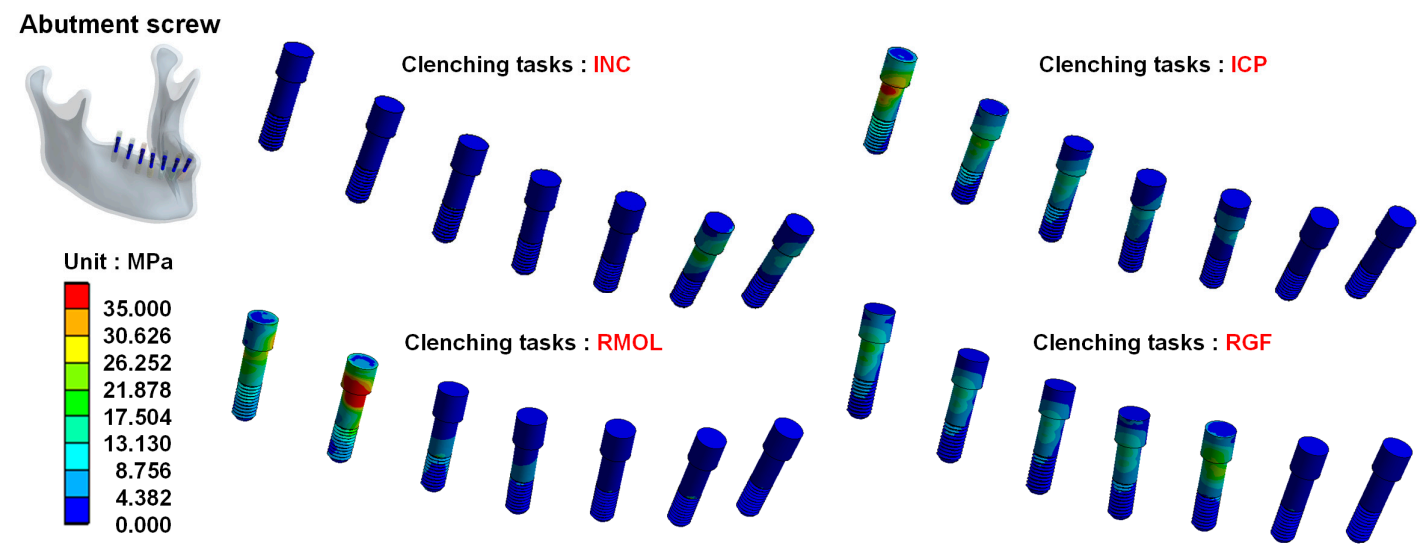

Figure 5. (a) Distribution of von Mises stress on the dental implants at different positions; (b) distribution of von Mises stress on the abutments of each dental implant system; (c) distribution of von Mises stress on the abutment screws. 
Table 4. The peak value of von Mises stress in the alveolar bone at each implant position.

\begin{tabular}{cccccccc}
\hline $\begin{array}{c}\text { Clenching } \\
\text { Tasks }\end{array}$ & $\begin{array}{c}\text { Central } \\
\text { Incisor }\end{array}$ & $\begin{array}{c}\text { Lateral } \\
\text { Incisor }\end{array}$ & Canine & $\begin{array}{c}\text { First } \\
\text { Premolar }\end{array}$ & $\begin{array}{c}\text { Second } \\
\text { Premolar }\end{array}$ & $\begin{array}{c}\text { First } \\
\text { Molar }\end{array}$ & $\begin{array}{c}\text { Second } \\
\text { Molar }\end{array}$ \\
\hline \multirow{2}{*}{ INC } & 8.6172 & 11.570 & 6.1677 & 8.6135 & 3.2200 & 1.7058 & 1.3761 \\
& $\mathrm{MPa}$ & $\mathrm{MPa}$ & $\mathrm{MPa}$ & $\mathrm{MPa}$ & $\mathrm{MPa}$ & $\mathrm{MPa}$ & $\mathrm{MPa}$ \\
ICP & 5.8776 & 4.0029 & 5.5820 & 10.713 & 18.101 & 19.713 & 24.500 \\
& $\mathrm{MPa}$ & $\mathrm{MPa}$ & $\mathrm{MPa}$ & $\mathrm{MPa}$ & $\mathrm{MPa}$ & $\mathrm{MPa}$ & $\mathrm{MPa}$ \\
\multirow{2}{*}{ RMOL } & 8.5377 & 9.9998 & 18.369 & 16.726 & 18.080 & 46.036 & 30.331 \\
& $\mathrm{MPa}$ & $\mathrm{MPa}$ & $\mathrm{MPa}$ & $\mathrm{MPa}$ & $\mathrm{MPa}$ & $\mathrm{MPa}$ & $\mathrm{MPa}$ \\
RGF & 8.0566 & 6.0974 & 8.1737 & 6.7470 & 9.7396 & 9.8921 & 8.1723 \\
& $\mathrm{MPa}$ & $\mathrm{MPa}$ & $\mathrm{MPa}$ & $\mathrm{MPa}$ & $\mathrm{MPa}$ & $\mathrm{MPa}$ & $\mathrm{MPa}$ \\
\hline
\end{tabular}

Table 5. The maximum von Mises stress values on the dental implant, abutment, and abutment screw of the dental implant systems at each implant position.

\begin{tabular}{|c|c|c|c|c|c|c|c|c|}
\hline $\begin{array}{l}\text { Clenching } \\
\text { Tasks }\end{array}$ & $\begin{array}{l}\text { Dental Implant } \\
\text { System Parts }\end{array}$ & $\begin{array}{l}\text { Central } \\
\text { Incisor }\end{array}$ & $\begin{array}{l}\text { Lateral } \\
\text { Incisor }\end{array}$ & Canine & $\begin{array}{c}\text { First } \\
\text { Premolar }\end{array}$ & $\begin{array}{l}\text { Second } \\
\text { Premolar }\end{array}$ & $\begin{array}{l}\text { First } \\
\text { Molar }\end{array}$ & $\begin{array}{l}\text { Second } \\
\text { Molar }\end{array}$ \\
\hline \multirow[t]{3}{*}{ INC } & Dental implant & $19.278 \mathrm{MPa}$ & $33.038 \mathrm{MPa}$ & & & & & \\
\hline & Abutment & $21.772 \mathrm{MPa}$ & $46.608 \mathrm{MPa}$ & - & - & - & - & - \\
\hline & Abutment screw & $15.538 \mathrm{MPa}$ & $21.346 \mathrm{MPa}$ & & & & & \\
\hline \multirow[t]{3}{*}{ ICP } & Dental implant & & & $24.704 \mathrm{MPa}$ & $25.698 \mathrm{MPa}$ & $39.887 \mathrm{MPa}$ & $67.858 \mathrm{MPa}$ & $83.292 \mathrm{MPa}$ \\
\hline & Abutment & - & - & $19.601 \mathrm{MPa}$ & $22.875 \mathrm{MPa}$ & $33.922 \mathrm{MPa}$ & $46.864 \mathrm{MPa}$ & $86.246 \mathrm{MPa}$ \\
\hline & Abutment screw & & & $12.443 \mathrm{MPa}$ & $11.547 \mathrm{MPa}$ & $22.712 \mathrm{MPa}$ & $27.760 \mathrm{MPa}$ & $54.372 \mathrm{MPa}$ \\
\hline \multirow[t]{3}{*}{ RMOL } & Dental implant & & & & & & $113.72 \mathrm{MPa}$ & $113.99 \mathrm{MPa}$ \\
\hline & Abutment & - & - & - & - & - & $101.89 \mathrm{MPa}$ & $87.328 \mathrm{MPa}$ \\
\hline & Abutment screw & & & & & & $58.614 \mathrm{MPa}$ & $42.373 \mathrm{MPa}$ \\
\hline \multirow[t]{3}{*}{ RGF } & Dental implant & & & $39.625 \mathrm{MPa}$ & $53.188 \mathrm{MPa}$ & $46.916 \mathrm{MPa}$ & $82.018 \mathrm{MPa}$ & $59.300 \mathrm{MPa}$ \\
\hline & Abutment & - & - & $56.089 \mathrm{MPa}$ & 39.316 MPa & $32.352 \mathrm{MPa}$ & $36.547 \mathrm{MPa}$ & $47.492 \mathrm{MPa}$ \\
\hline & Abutment screw & & & $39.795 \mathrm{MPa}$ & $21.953 \mathrm{MPa}$ & $30.517 \mathrm{MPa}$ & $29.469 \mathrm{MPa}$ & $42.317 \mathrm{MPa}$ \\
\hline
\end{tabular}

\section{Discussion}

Due to advances in technology, dental implants have become the most commonly used treatment for patients with partial or complete tooth loss. As a result, many medical device manufacturers and implant researchers have conducted studies on implant design. However, thus far, most mechanical studies have only considered simple forces and have not considered the impact of the implant positions and the different occlusion conditions. In addition, since the mechanical analysis will become highly complicated when taking into account the different occlusion conditions, it is difficult for clinical researchers to conduct studies that evaluate the effect of different occlusion conditions on dental implants, which explains why there is no reference available on this topic. Therefore, this study successfully conducted a biomechanical analysis of the impact of four common occlusion conditions on the different positions of dental implants using the finite element method. The results of this study provide researchers with a mechanical reference of the impact of the different positions and different occlusion conditions on dental implants.

In this study, after the FEA was completed, due to the settings of the boundary conditions, the reaction forces at the TMJ and the fixed ends of the abutments of the dental implant systems could be observed. Among the four occlusion conditions, ICP generate significantly higher reaction forces at the TMJ. ICP mainly simulates the maximum intercuspation of the posterior teeth and mainly affects the canine, premolar, and molar. Although there is only a larger reaction force on the fixed top end of the abutment on the second molar $(161.13 \mathrm{~N})$, the acting teeth are canine $(28.819 \mathrm{~N})$, first premolar $(40.884 \mathrm{~N})$, second premolar $(61.691 \mathrm{~N})$, first molar $(80.5883 \mathrm{~N})$ and second molar, thus their total force will be larger. Therefore, there is a higher reaction force on the TMJ under the occlusion of ICP. From the previous literature [31,32], if the dental implant is subjected to relatively large external forces, the diameter of the dental implant can be increased. The dental implant can improve the transfer of occlusion load to bone tissue, thereby reducing the stress on the mandible under larger loads. Furthermore, ICP generate higher reaction forces on TMJ. The TMJ is subjected 
to the loading, which may cause deformations and tensions in cartilaginous structures [33]. RMOL mainly simulates the contact of the posterior teeth on the right side (unilateral). As an unbalanced occlusion, besides the fact that the occlusal force is concentrated on the posterior teeth, the external force applied by the muscles is also high. Thus, the reaction forces on the first molar $(261.09 \mathrm{~N})$ and second molar $(214.91 \mathrm{~N})$ are high, especially the reaction force on the first molar near the mesial side. Therefore, to avoid postoperative failure in patients, implantations in the posterior teeth region can use thicker implants capable of bearing greater external forces. Furthermore, in INC and RGF occlusions, the reaction forces on the fixed top ends of the abutment are relatively low (However, in the case of INC occlusion, the reaction force value of the fixed top of the abutment on the lateral incisor reaches $70.431 \mathrm{~N}$. This value is greater than in some cases under the occlusion of ICP). INC mainly simulates the contact between incisal edges. Since the muscles that produce this movement do not exert a strong force, only a small reaction force is generated on the central incisor. RGF mainly simulates the lateral movement of the right posterior teeth. Thus, the vertical force exerted by the muscles to the mandible is not strong, thus the reaction forces exerted on the canine, first premolar, second premolar, first molar, and second molar are also weak. In addition, according to the results of this study, the reaction force on the posterior region $(26.968 \mathrm{~N}$ to $261.09 \mathrm{~N})$ during occlusion is not necessarily greater than that on the anterior region ( $28.819 \mathrm{~N}$ to $70.431 \mathrm{~N})$. The magnitude of the force on the dental implant is mainly determined by the external force given by the muscle on the mandible in different occlusion situations. The results of the FEA showed the external forces (magnitude and direction) applied to the dental implants at different positions under the four occlusal conditions. Thus, when conducting in vitro experiments or FEA of the biomechanics of dental implants in the future, the results of this study (the reaction force on the fixed top end of the abutment of each dental implant system) can be used as a reference for the setting of the loading conditions. Whereby different implant designs at different positions can be evaluated and that studies on the biomechanics of dental implants will not be limited by the application of a single vertical, horizontal, or oblique external force.

The distribution of the von Mises stress in the entire mandibular bone shows that high stress occurs at the neck near the TMJ. This is because the cross-sectional area here is small, and thus when a force is passed, higher stress will be generated. In addition, in teeth regions where high stress is generated, high stress will also be generated on the alveolar bone in these regions due to the different occlusion conditions and the different dental implant systems involved (ICP and RMOL occlusions will generate high stress on the alveolar bone, which is consistent with the results of previous studies [24]. However, RGF occlusion has a smaller impact on the stress on the alveolar bone). Moreover, when examining the stress on the alveolar bone in areas of a single tooth, it can be seen that areas in connection with the cortical bone have higher stress. The production of this high stress can be explained by Hooke's law (stress $=$ Young's Modulus $\times$ strain). When the dental implant system receives an external force, it will have a slight downward displacement, compressing the alveolar bone and generating the same displacement at the junction of the cortical bone and trabecular bone (creating the same strain here). At the same time, the stress is proportional to the Young's Modulus. In this study, the Young's Modulus of the cortical bone is $13,800 \mathrm{MPa}$, and that of the trabecular bone is $345 \mathrm{MPa}$. Thus, the cortical bone above the alveolar bone has a higher stress. Therefore, in the design of some implants, the number of threads is increased at the neck of the implant, increasing its contact area with the surface of the alveolar bone, preventing the dental implant system from loosening up when external forces are exerted, thereby enhancing the success rate of implantation.

The distribution of von Mises stress on the dental implant system shows that the high stresses on the dental implants under the impact of external forces mainly arise near the neck of the dental implant, where the dental implant contacts with the abutment. Therefore, when the tooth receives an external force, it will directly deform the neck of the dental implant. According to Hooke's law, high stress will be generated in this area. In addition, it was found that the alveolar bone of the implants adjacent to the implants that were affected by external forces will also experience high stress due to deformation. Moreover, when examining the stress on the abutment and abutment screw, it can be seen that the high 
stress on abutment arises at its junction with the dental implant. The high stress on the abutment screw arises in the area where the screw head is connected to the abutment, also corresponding to the area where the geometric shape of the screw head and screw bends. Therefore, the design of the abutments and abutment screws should avoid the generation of high stress by the geometric shape. Otherwise, since the patient will chew with the dental implant system for a long time, the dental implant system may be damaged due to fatigue.

This study has some limitations. In the FEA, all the material properties were assumed to be homogeneous, isotropic, and linearly elastic. These assumptions were in accordance with previous studies $[34,35]$, and the purpose was to simplify the simulation in this study and allow easier comparisons of the results. Although the results of the research will be slightly different from the actual situation, the main trends of the results will still hold true. In addition, the computer simulation model used in this study was simplified. We only constructed models of dental implants and did not include the crowns. The main reason for this is that the structures and shapes of the teeth can be different. Our study aimed to examine how dental implants at different positions are impacted by the occlusal forces. To reduce the confounding effect from the shapes and structures of the crowns of the different teeth, we only applied external forces to the abutments to facilitate the evaluation of the impact at different positions. Furthermore, our model used seven dental implants (normally, the model with 14 dental implants should be established in this study). The main reason is that our dental implant model has created threads, if there are 14 dental implant systems on this finite element model, it will increase the numbers of nodes and elements on the computer model, which will increase the difficulty of model meshing and analysis. Therefore, we made some simplifications for the model, we created the incisor regions, canine regions, premolar regions, and molar regions for the left side of the mandible based on the previous study [22,23].) Moreover, since the third molar is the wisdom teeth, we did not consider situations where an implant is placed at this position. Furthermore, the sizes of the dental implants at the different positions were all the same, in order to eliminate the confounding effect of the different sizes when evaluating the results. After the series of simplifications, our study is different from the actual situation, but we were able to obtain clearer trends and results regarding the topics of interest in this study.

This study examined the effect of four common occlusion conditions on the different positions of dental implants using the finite element method. The results of the study show that the dental implant may receive greater external forces in ICP and RMOL occlusions. Although the numerical values measured in this study may be slightly different from those measured in clinical scenarios, the results of this study can provide a mechanical reference for scholars who study and design dental implants. In the future, the results of this study can be used to conduct more mechanical studies on the occlusion conditions related to dental implants and to carry out more detailed designs and improvements of the implants, thus that patients requiring dental implants can achieve better health outcomes.

\section{Conclusions}

This study examined the impact of different occlusion conditions on dental implants with different positions using the finite element method. According to this study, it was concluded that:

1. The reaction force on the posterior region is not necessarily greater than that on the anterior region. The magnitude and direction of the bite force are mainly affected by different occlusion conditions.

2. Under the occlusion conditions of RMOL, the dental implant system and the entire mandible experienced significantly higher stress. The reaction force on the fixed-top end of the abutment in the dental implant system is also stronger.

3. Under the occlusion conditions of ICP, there is a higher reaction force on the TMJ.

4. The detailed information of the reaction force on the fixed-top end of the dental implant system can provide a biomechanical reference for dental implant design and dental implant biomechanical research in the future. They will be able to take into consideration the external forces that the 
implants receive at different positions and design dental implants specific for different positions, making the implants more suitable for clinical use and reducing the failure rate after implantation.

Author Contributions: Conceptualization, P.-J.L. and K.-C.S.; methodology, K.-C.S.; data curation, P.-J.L.; writing-original draft preparation, P.-J.L. and K.-C.S.; writing-review and editing, P.-J.L. and K.-C.S. All authors have read and agreed to the published version of the manuscript.

Funding: This research received no external funding.

Acknowledgments: The authors acknowledge the United States National Library of Medicine (NLM) and the Visible Human Project as the image source to build the FEA model in this study. In addition, we also would like to thank the 3D Printing Research and Development Group, Taichung Veterans General Hospital, and hospital plan (TCVGH-1097318C) for helping us to build the simulation computer model of this study.

Conflicts of Interest: The authors declare no conflict of interest.

\section{References}

1. Ashley, E.T.; Covington, L.L.; Bishop, B.G.; Breault, L.G. Ailing and failing endosseous dental implants: A literature review. J. Contemp. Dent. Pract. 2003, 4, 35-50. [PubMed]

2. Dos Santos, M.C.L.G.; Campos, M.I.G.; Line, S.R.P. Early dental implant failure: A review of the literature. Braz. J. Oral Sci. 2002, 1, 103-111.

3. Hansson, S. A conical implant-abutment interface at the level of the marginal bone improves the distribution of stresses in the supporting bone: An axisymmetric finite element analysis. Clin. Oral Implant. Res. 2003, 14, 286-293. [CrossRef]

4. El-Anwar, M.I.; El-Zawahry, M.M. A three dimensional finite element study on dental implant design. J. Genet. Eng. Biotechnol. 2011, 9, 77-82. [CrossRef]

5. Bozkaya, D.; Muftu, S.; Muftu, A. Evaluation of load transfer characteristics of five different implants in compact bone at different load levels by finite elements analysis. J. Prosthet. Dent. 2004, 92, 523-530. [CrossRef]

6. Baggi, L.; Cappelloni, I.; Di Girolamo, M.; Maceri, F.; Vairo, G. The influence of implant diameter and length on stress distribution of osseointegrated implants related to crestal bone geometry: A three-dimensional finite element analysis. J. Prosthet. Dent. 2008, 100, 422-431. [CrossRef]

7. Ryu, H.-S.; Namgung, C.; Lee, J.-H.; Lim, Y.-J. The influence of thread geometry on implant osseointegration under immediate loading: A literature review. J. Adv. Prosthodont. 2014, 6, 547-554. [CrossRef] [PubMed]

8. Wu, S.-W.; Lee, C.-C.; Fu, P.-Y.; Lin, S.-C. The effects of flute shape and thread profile on the insertion torque and primary stability of dental implants. Med. Eng. Phys. 2012, 34, 797-805. [CrossRef] [PubMed]

9. Bulaqi, H.A.; Mashhadi, M.M.; Safari, H.; Samandari, M.M.; Geramipanah, F. Effect of increased crown height on stress distribution in short dental implant components and their surrounding bone: A finite element analysis. J. Prosthet. Dent. 2015, 113, 548-557. [CrossRef]

10. Chang, P.-K.; Chen, Y.-C.; Huang, C.-C.; Lu, W.-H.; Chen, Y.-C.; Tsai, H.-H. Distribution of micromotion in implants and alveolar bone with different thread profiles in immediate loading: A finite element study. Int. J. Oral Maxillofac. Implant. 2012, 27, e96-e101.

11. Verri, F.R.; de Souza Batista, V.E.; Santiago, J.F., Jr.; de Faria Almeida, D.A.; Pellizzer, E.P. Effect of crown-to-implant ratio on peri-implant stress: A finite element analysis. Mater. Sci. Eng. C 2014, 45, 234-240. [CrossRef] [PubMed]

12. Kong, L.; Liu, B.; Li, D.; Song, Y.; Zhang, A.; Dang, F.; Qin, X.; Yang, J. Comparative study of 12 thread shapes of dental implant designs: A three-dimensional finite element analysis. World J. Model. Simul. 2006, 2, 134-140.

13. Ananth, H.; Kundapur, V.; Mohammed, H.; Anand, M.; Amarnath, G.; Mankar, S. A review on biomaterials in dental implantology. Int. J. Biomed. Sci. 2015, 11, 113. [PubMed]

14. Schwitalla, A.; Abou-Emara, M.; Spintig, T.; Lackmann, J.; Müller, W. Finite element analysis of the biomechanical effects of PEEK dental implants on the peri-implant bone. J. Biomech. 2015, 48, 1-7. [CrossRef] [PubMed] 
15. Marcián, P.; Borák, L.; Valášek, J.; Kaiser, J.; Florian, Z.; Wolff, J. Finite element analysis of dental implant loading on atrophic and non-atrophic cancellous and cortical mandibular bone-a feasibility study. J. Biomech. 2014, 47, 3830-3836. [CrossRef]

16. Van Eijden, T. Three-dimensional analyses of human bite-force magnitude and moment. Arch. Oral Biol. 1991, 36, 535-539. [CrossRef]

17. Shim, H.W.; Yang, B.-E. Long-term cumulative survival and mechanical complications of single-tooth Ankylos Implants: Focus on the abutment neck fractures. J. Adv. Prosthodont. 2015, 7, 423-430. [CrossRef]

18. Amid, R.; Ebrahimi, N.; Kadkhodazadeh, M.; Mirakhori, M.; Mehrinejad, P.; Nematzadeh, F.; Dehnavi, F. Clinical evaluation of a new device to measure maximum bite force. Dentist. Case. Rep. 2018, 2, $26-29$.

19. Chieruzzi, M.; Pagano, S.; Cianetti, S.; Lombardo, G.; Kenny, J.M.; Torre, L. Effect of fibre posts, bone losses and fibre content on the biomechanical behaviour of endodontically treated teeth: 3D-finite element analysis. Mater. Sci. Eng. C Mater. Biol. Appl. 2017, 74, 334-346. [CrossRef]

20. Van Staden, R.C.; Guan, H.; Loo, Y.C. Application of the finite element method in dental implant research. Comput. Methods Biomech. Biomed. Eng. 2006, 9, 257-270. [CrossRef]

21. Korioth, T.W.; Hannam, A.G. Mandibular forces during simulated tooth clenching. J. Orofac. Pain 1994, 8, 179-189.

22. Huang, H.-L.; Su, K.-C.; Fuh, L.-J.; Chen, M.Y.; Wu, J.; Tsai, M.-T.; Hsu, J.-T. Biomechanical analysis of a temporomandibular joint condylar prosthesis during various clenching tasks. J. Cranio-MaxilloFac. Surg. 2015, 43, 1194-1201. [CrossRef] [PubMed]

23. Chang, Y.-H.; Chan, M.-Y.; Hsu, J.-T.; Hsiao, H.-Y.; Su, K.-C. Biomechanical Analysis of the Forces Exerted during Different Occlusion Conditions following Bilateral Sagittal Split Osteotomy Treatment for Mandibular Deficiency. Appl. Bionics Biomech. 2019, 2019, 4989013. [CrossRef] [PubMed]

24. Luo, D.; Rong, Q.; Chen, Q. Finite-element design and optimization of a three-dimensional tetrahedral porous titanium scaffold for the reconstruction of mandibular defects. Med. Eng. Phys. 2017, 47, 176-183. [CrossRef] [PubMed]

25. Hijazi, L.; Hejazi, W.; Darwich, M.A.; Darwich, K. Finite element analysis of stress distribution on the mandible and condylar fracture osteosynthesis during various clenching tasks. J. Oral. Maxillofac. Surg. 2016, 20, 359-367. [CrossRef]

26. Kang, X.; Li, Y.; Wang, Y.; Zhang, Y.; Yu, D.; Peng, Y. Relationships of Stresses on Alveolar Bone and Abutment of Dental Implant from Various Bite Forces by Three-Dimensional Finite Element Analysis. Biomed Res. Int. 2020, 2020, 7539628. [CrossRef]

27. Li, T.; Hu, K.; Cheng, L.; Ding, Y.; Ding, Y.; Shao, J.; Kong, L. Optimum selection of the dental implant diameter and length in the posterior mandible with poor bone quality-A 3D finite element analysis. Appl. Math. Model. 2011, 35, 446-456. [CrossRef]

28. Jo, J.-Y.; Yang, D.-S.; Huh, J.-B.; Heo, J.-C.; Yun, M.-J.; Jeong, C.-M. Influence of abutment materials on the implant-abutment joint stability in internal conical connection type implant systems. J. Adv. Prosthodont. 2014, 6, 491-497. [CrossRef]

29. Huang, H.-L.; Hsu, J.-T.; Fuh, L.-J.; Tu, M.-G.; Ko, C.-C.; Shen, Y.-W. Bone stress and interfacial sliding analysis of implant designs on an immediately loaded maxillary implant: A non-linear finite element study. J. Dent. 2008, 36, 409-417. [CrossRef]

30. Su, K.-C.; Chang, C.-H.; Chuang, S.-F.; Ng, E.Y.-K. Biomechanical evaluation of endodontic post-restored teeth-finite element analysis. J. Mech. Med. Biol. 2013, 13, 1350012. [CrossRef]

31. Himmlova, L.; Dostalova, T.; Kacovsky, A.; Konvickova, S. Influence of implant length and diameter on stress distribution: A finite element analysis. J. Prosthet. Dent. 2004, 91, 20-25. [CrossRef] [PubMed]

32. Santiago Junior, J.F.; Pellizzer, E.P.; Verri, F.R.; de Carvalho, P.S. Stress analysis in bone tissue around single implants with different diameters and veneering materials: A 3-D finite element study. Mater. Sci. Eng. C Mater. Biol. Appl. 2013, 33, 4700-4714. [CrossRef] [PubMed]

33. Koolstra, J.H.; van Eijden, T.M. Combined finite-element and rigid-body analysis of human jaw joint dynamics. J. Biomech. 2005, 38, 2431-2439. [CrossRef] [PubMed] 
34. Sevimay, M.; Turhan, F.; Kiliçarslan, M.; Eskitascioglu, G. Three-dimensional finite element analysis of the effect of different bone quality on stress distribution in an implant-supported crown. J. Prosthet. Dent. 2005, 93, 227-234. [CrossRef] [PubMed]

35. Kong, L.; Zhao, Y.; Hu, K.; Li, D.; Zhou, H.; Wu, Z.; Liu, B. Selection of the implant thread pitch for optimal biomechanical properties: A three-dimensional finite element analysis. Adv. Eng. Softw. 2009, 40, 474-478. [CrossRef]

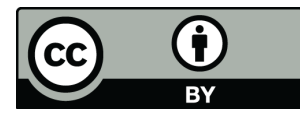

(C) 2020 by the authors. Licensee MDPI, Basel, Switzerland. This article is an open access article distributed under the terms and conditions of the Creative Commons Attribution (CC BY) license (http://creativecommons.org/licenses/by/4.0/). 